\title{
A Computer-Aided Tolerance Specification Method Based on Multiple Attributes Decision-Making
}

\author{
Qijian Zhao ${ }^{1 *}$, Tukun $\mathrm{Li}^{2}$, Yanlong $\mathrm{Cao}^{3}$, Jiangxin $\mathrm{Yang}^{3}$, Xiangqian Jiang ${ }^{2}$ \\ ${ }^{1}$ Institute of Mechanical Manufacturing Technology, China Academy of Engineering Physics, Mianyang, 621900, China \\ ${ }^{2}$ EPSRC Future Advanced Metrology Hub, Centre for Precision Technologies, School of Computing and Engineering, \\ University of Huddersfield, Huddersfield, HDI $3 D H, U K$ \\ ${ }^{3}$ Key Laboratory of Advanced Manufacturing Technology of Zhejiang Province, College of Mechanical Engineering, Zhejiang \\ University, Hangzhou, 310027, China \\ * Corresponding author. Tel: +86-0816-2491346; Fax: +86-0816-2491346; E-mail: zqj@ zju.edu.cn
}

\begin{abstract}
:
In the mechanical product design, tolerance specification is a crucial process to select tolerance types to control the geometrical variation of the features on a workpiece. Tolerance specification is a kind of decision-making process which needs to consider many influential factors of the manufacturing cost and quality requirement of a workpiece. In this context, those factors are classified into two categories, that of static factors from the rules and standards, and that of dynamic factors based on the manufacturing site's information. This paper presents a novel method for computer-aided tolerance specification to evaluate both types of factors while the traditional methods only take the static factors into considerations. Those factors are assessed by the developed MADM (Multiple Attributes Decision-Making) algorithm, assisted with the rule-based algorithm and Axiomatic Design algorithm. A case study is undertaken, and its result shows that the effect of dynamic factors on the output of tolerance specification. The results adhere to the ISO standard.
\end{abstract}

Keywords: geometric tolerances; tolerance specification; Computer-Aided Tolerancing (CAT); Multiple Attributes Decision-Making (MADM); Axiomatic Design (AD).

\section{Introduction}

It is of importance that a mechanical engineer balances the quality requirement and the manufacturing cost of a workpiece in the design stage. To this end, the tolerance design is usually employed after the functional/structure design [1]. Tolerance design is to develop the permissible variation limit of the dimensions and geometric parameters of workpieces, which aims to address functional and assembly requirements under a limited cost. Tolerance design usually consists of three tasks: tolerance specification, tolerance allocation and tolerance analysis [2-6]. This paper mainly focuses on the tolerance specification, which is to determine Datum Reference Frame (DRF) and select the geometrical tolerances on a workpiece.

Some works have been done for the computer-aided tolerance specifications via different approaches to model information from various resources. Clemént [7, 8] introduced the technologically and topologically related surfaces (TTRS) model which calculates the extracted information of the surfaces from a geometric model, and it requires a designer's experience for further selection. The TTRS model has been further optimised $[9,10]$. Variational geometric 
constraints network is defined to generate a network to model the relationship between features and specified tolerance types by $\mathrm{Hu}$ [11]. Zhang [12] proposed an algorithm for specification by introducing the polychromatic set theory. Qin $[13,14]$ suggested and developed an ontology-based model for tolerance specification, which the model has been further developed by Qie [15]. The assembly relationship of the parts is also considered. Anselmetti [16, 17] defined the positioning table method, which was implemented in Quick GPS [18]. Cao [19] applied graph theory to develop the positioning table method. Qin [20] introduced a top-down strategy to carry out tolerance specification for an arbitrary assembly designed in a Computer-Aided Design (CAD) system. The empirical knowledge can also be useful. Haghighi [21] have developed a set of rules for the generation of the tolerance specification. Armillotta [22] proposed a tolerance specification method by combining experimental factors and assembly relation. Some tolerance specification methods are developed based on previous cases. Cao [23] proposed a statistical learning-based method for datum selection of tolerance specification. Qin [24] introduced a case-based reasoning approach to developing the ontology-based tolerance specification method.

Table 1 lists a comparison of the factors considered in some typical tolerance specification methods. The factors can be classified into five groups, namely geometry, position, assembly, experience and cases. Those factors (refers to static factors in this paper) are developed based on the rules, standards, previous experience/cases. In the manufacturing site, an engineer must also consider the factors related to her/his environment (e.g. the ability of the measuring instrument, the up-limited of manufacturing cost, the level of the quality requirement and the precision of machine tools). Those factors are related to the conditions of the work floor (refers to dynamic factors in this context). However, the current computer-aided method for the tolerance specification did not consider dynamic factors in their evaluation.

Table 1 Comparison of the factors in some tolerance specification methods

\begin{tabular}{cccccccc}
\hline $\begin{array}{c}\text { The utilisation of } \\
\text { the factors }\end{array}$ & Geometry & Position & Assembly & $\begin{array}{c}\text { Empirical } \\
\text { rules }\end{array}$ & $\begin{array}{c}\text { Cases } \\
\text { Compatible }\end{array}$ & $\begin{array}{c}\text { Standard } \\
\text { with TTRS }\end{array}$ & \begin{tabular}{c} 
[25, 26] \\
\hline Clemént [8]
\end{tabular} \\
Zhang [12] & $\checkmark$ & $\checkmark$ & $\checkmark$ & & $\checkmark$ & ISO \\
Anselmetti [18] & $\checkmark$ & $\checkmark$ & $\checkmark$ & & $\checkmark$ & ISO \\
Armillotta [22] & $\checkmark$ & $\checkmark$ & $\checkmark$ & $\checkmark$ & & $\checkmark$ & ASME \\
Qin [24] & $\checkmark$ & $\checkmark$ & $\checkmark$ & & $\checkmark$ & $\checkmark$ & ASME \\
\hline
\end{tabular}

There are several reasons to consider the impact of dynamic factors in the computer-aid of tolerance specification, as follows.

1. In current practice, dynamic factors play an essential role in the development of tolerance specification. According to a survey and interviews were undertaken in 2019 [47], engineers in the manufacturing site are often determined tolerance specification via both factors. Static factors must be followed due to that the rules are standardised and mathematically defined. It is often that the same static factors can produce several tolerance specification schemes. In this situation, an engineer will consider the dynamic factors to decide the final choice. For example, a factory with many developed gauges will prefer to use a tolerance scheme employed the dependent rule, and one with more digital instruments (e.g. CMM) would like to use the scheme developed by the independent rule

2. In the future digital/smart manufacturing, dynamic factors will play an essential role in the tolerance design. Currently, the exchange of data/information is very limited in the life 
cycle of a product. Therefore, a designer does not consider the dynamic factor when he/she design tolerance due to the lack of information. In the shift toward industry 4.0, the data and information from the machine tools and measurement instruments will be available, and knowledge will be accumulated with the aid of artificial intelligence. A designer will make a better decision in the development of tolerance with considering dynamical factors, together with the static factors.

To this end, this paper will design and develop a computer-aided algorithm to produce tolerance specification by assessing both dynamic factors and static factors. Dynamic factors are investigated and classified. Static factors produce a list of geometric tolerance to describe a feature on a workpiece. MADM algorithm is developed to assess the weight of dynamic factors on each tolerance scheme. AD algorithm is implemented to evaluate the outcome of MADM algorithm and to select geometric tolerance. MADM method is the first time to be introduced into this field, and the $\mathrm{AD}$ approach has been used in the assessment of one type of tolerance, namely flatness. Thus, some groundwork about MADM approach and AD approach is presented in Section 2. The developed algorithms are detailed in Section 3. Section 4 presents a case study to illustrate the use of the proposed method. The conclusion and future work are summarised in Section 5.

\section{Preliminary}

\subsection{MADM methods}

Multiple Attributes Decision Making (MADM) methods are an approach to solve a selection problem with the aim of "making preference decisions over the available alternatives that are characterised by multiple attributes" [31]. Their historical origins can be traced back to Nicolas Bernoulli in 1738 when he proposed the concept of utility function to reflect human pursuit [31]. The applications of MADM methods are employed in many fields, such as computer science [32] and engineering applications [33]. In the field of tolerance specification, it is probably the first application of the MADM method.

The MADM methods integrate the attribute values of each candidate scheme into a matrix and then apply an algorithm to calculate the priority of each scheme based on the matrix [31]. Each value of the matrix could be number, interval or fuzzy set. In general, the form of MADM is expressed as:

$$
\begin{gathered}
\text { optimize }\left[u_{1}(x), u_{2}(x), \ldots, u_{m}(x)\right] \\
\text { Subject To: } x \in X
\end{gathered}
$$

where $X=\left\{x_{1}, x_{2}, \ldots, x_{n}\right\}\left(n \in N^{+}\right)$represents the set of candidate schemes; $x$ represents a scheme of. $\boldsymbol{U}=\left\{u_{1}, u_{2}, . ., u_{m}\right\}\left(m \in N^{+}\right)$is the attributes set and $u_{1}, u_{2}, . ., u_{m}$ represent the attributes. The matrix is $\boldsymbol{C}=\left[c_{i j}\right]_{n \times m}$ a decision-making matrix, where $c_{i j}=u_{j}\left(x_{i}\right)\left(i \in[1, n], j \in[1, m], i, j \in N^{+}\right)$. A MADM algorithm is to select an optimal scheme $x$ based on $\boldsymbol{C}$.

For example, there is a reducer selection problem. The candidate reducers set is $\left\{x_{1}, x_{2}, x_{3}, x_{4}\right\}$. The price $\left(y_{1}\right)$, efficiency $\left(y_{2}\right)$ and weight $\left(y_{3}\right)$ are the attributes. In this example, the preference is the lower price, lower weight and higher efficiency. The weights of the attributes are known, i.e. $\boldsymbol{w}=\left[\begin{array}{lll}0.2 & 0.5 & 0.3\end{array}\right]^{T}$. The calculation for the optimal scheme is illustrated in Fig. 1. Firstly, the attribute values of the schemes are determined. Secondly, the decision-making matrix is normalised. Thirdly, the indexes are calculated and the optimal reducer selection scheme is determined. It is often that the weight of each attribute is unknown. The entropy algorithm [44, 45], which evaluates 
the unknown weight based on the design matrix, can be used. This method will be used in the Section 3 .

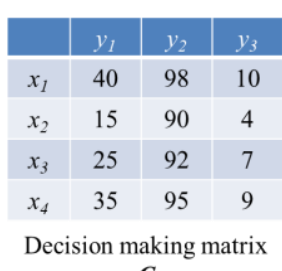

C

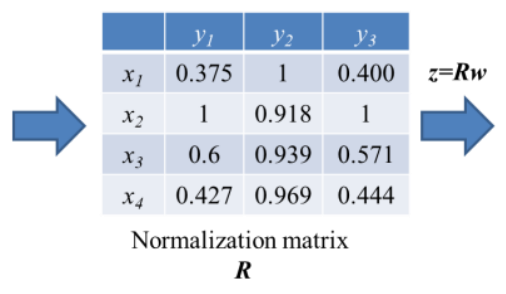

Fig. 1 The optimal reducer selection procedures by MADM approach

\subsection{AD method}

Axiomatic Design (AD) is a design methodology to address the transformation issues of customer needs into functional requirement and design parameter. It was proposed by Suh [27] in the 1990s and has been widely used to address the fundamental issues in Taguchi methods. In the field of computer-aided tolerance specification, an $\mathrm{AD}$ method for specification was firstly introduced in 2018 [30]. It shows that the tolerance specification can be interpreted to a design problem.

AD method uses two types of axioms, namely independent axiom and information axiom. The independent axiom (i.e. maintain the independence of the functional requirements) means that the functional requirements must comprise a minimum set of independent requirements that utterly satisfy the customer needs to provide a robust design. The information axiom (i.e. minimise the information content of the design) means that the design with the highest probability of success is the best. In a design problem, a set of Functional Requirements (FRs) are related to a set of Design Parameters (DPs) by a Design Matrix $\boldsymbol{A}$, which can be represented by

$$
\begin{gathered}
{[F R]=\left[A_{m \times n}\right][D P], A_{i j}=\frac{\partial F R_{i}}{\partial D P_{j}}, i=1, \ldots, m ; j=1, \ldots, n} \\
\text { Subject To: }\left\{C_{1}\right\},\left\{C_{2}\right\}, \ldots,\left\{C_{k}\right\}
\end{gathered}
$$

where $[F R]$ is the vector of functional requirements, $\left[A_{\mathrm{m} \times \mathrm{n}}\right]$ is the design matrix and $[D P]$ is the vector of design parameters. $m$ and $n$ are the numbers of FRs and DPs. $\left\{C_{1}\right\},\left\{C_{2}\right\}, \ldots,\left\{C_{\mathrm{k}}\right\}$ represents the constraints of the design, such as the value range of the DPs. In this paper, the FR is the variation of a feature, and DP is applied to limit the variation, i.e. a geometric tolerance of the candidate tolerances.

\section{The MADM method for computer-aided tolerance specification}

\subsection{The framework}

Fig. 2 illustrates the framework of the implementation of the MADM method, and Table 2 lists the descriptions of the key terms used in this paper. The input data are features on the CAD model of a workpiece, together with factors to develop its tolerance specification. The classification of the factors is detailed in Section 3.1.1. The output data are the developed geometrical tolerances, together with the selected Datum Reference Frame (DRF), which is an orthogonal coordinate system for geometrical tolerance. The data is processed by a set of algorithms and operations: A Minimum Geometric Datum Elements based algorithm (MGDE-based algorithm) to generate DRF; a rule- 
based operation to create the candidate schemes set $\boldsymbol{S}$; MADM method to select optimal scheme (detailed in Section 3.2), and AD algorithm to determine geometrical tolerances (documented in Section 3.3). The MGDE-based algorithm and the rule-based operation are developed based on previous work [8,11-14], and will be presented in a case study in Section 4.

All methods listed in Table 1 are compatible with TTRS, and they are adhering to the ISO standards or ASME standards correspondingly. For the proposed method, therefore, we select two criteria, that of to be compliable with TTRS, and that of to adhere to the ISO standards.

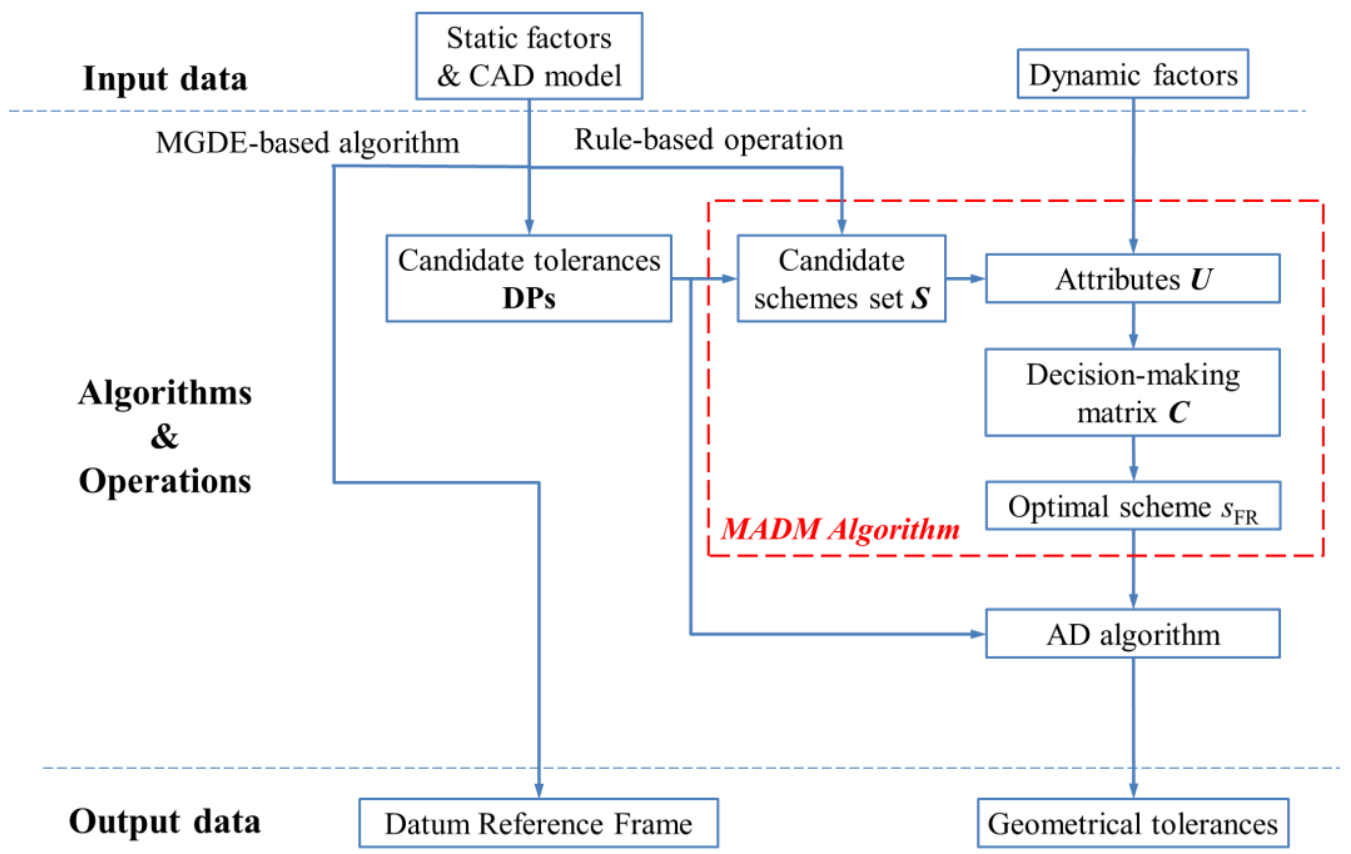

Fig. 2 The framework of the MADM method, assisted with the AD algorithm

Table 2 Key terms used in the MADM algorithm

\begin{tabular}{|c|c|c|c|}
\hline Symbol & Name & Description & Example/Note \\
\hline$u$ & Dynamic Factor & $\begin{array}{l}\text { A variable to describe factor from the } \\
\text { manufacturing/measuring site. }\end{array}$ & Quality, precision, cost, ... \\
\hline$D P$ & $\begin{array}{l}\text { Design } \\
\text { parameter }\end{array}$ & $\begin{array}{l}\text { Candidate tolerances for FR (Functional } \\
\text { requirement) }\end{array}$ & $\begin{array}{l}\text { Flatness is a DP to specify form } \\
\text { variation. }\end{array}$ \\
\hline$F R$ & $\begin{array}{l}\text { Functional } \\
\text { Requirement }\end{array}$ & $\begin{array}{l}\text { Variations after decomposition } \\
\text { operations }\end{array}$ & $\begin{array}{l}\boldsymbol{F R}=\left\{F R_{1}, F R_{2}, F R_{3}\right\}, \text { where } \\
F R_{1}, F R_{2} \text { and } F R_{3} \text { represent the } \\
\text { translation, rotation and form } \\
\text { variation, respectively (see } \\
\text { Appendix 1) }\end{array}$ \\
\hline $\boldsymbol{U}$ & Attribute & $\begin{array}{l}\text { A preference described as a set of } \\
\text { dynamic factors }\end{array}$ & $\boldsymbol{U}=\left\{u_{1}, u_{2}, \ldots, u_{m}\right\}\left(m \in N^{+}\right)$ \\
\hline$S$ & $\begin{array}{l}\text { candidate } \\
\text { schemes set }\end{array}$ & $\begin{array}{l}\text { A set }\left(\boldsymbol{S}=\left\{s_{1}, s_{2}, \ldots, s_{n}\right\}\left(n \in N^{+}\right)\right) \text {of } \\
\text { decomposition scheme, namely } s_{i} \text {, } \\
\text { which is a selection of the } \\
\text { decomposition of a feature. }\end{array}$ & see Appendix 1 \\
\hline
\end{tabular}

$\boldsymbol{C} \quad$ Decision- $\quad$ A matrix to integrate the values of the An element of $\boldsymbol{C}$ is calculated as




\begin{tabular}{|c|c|c|c|}
\hline & making matrix & attributes of the candidate schemes. & $\begin{array}{l}c_{i j}=u_{j}\left(s_{i}\right)(i \in[1, n], j \in[1, m], i, j \\
\left.\in N^{+}\right) .\end{array}$ \\
\hline \multirow[t]{2}{*}{$S_{F R}$} & Optimal & A scheme selected from $\boldsymbol{S}$ & \\
\hline & Scheme & & \\
\hline
\end{tabular}

\subsection{Classification of the factors}

A dynamic factor is a quantified descriptor of a grouped of contributors for the tolerancing specification from the manufacturing/measuring site. A designer can change the weight of dynamic factors based on her/his requirement. In this paper, the dynamic factors were selected as the outcome of the literature review, a recent survey and interviews of experienced engineers. Some of them are listed in Fig. 3, and this paper will focus on five significant groups of factors: Quality, Precision, Applicative, Verification and Cost. They will be described as the corresponding attributes of a feature. Quality attribute estimates the quality requirements in manufacturing. Precision attribute quantifies precision levels. Applicative attribute accesses the agreement between the design criteria and functional requirement. Verification attribute estimates the complexity of the inspection. Cost attribute measures the cost based on tolerance requirements. Note that those factors are often conflicting. For example, we cannot make a selection to have the highest precision and the lowest cost.

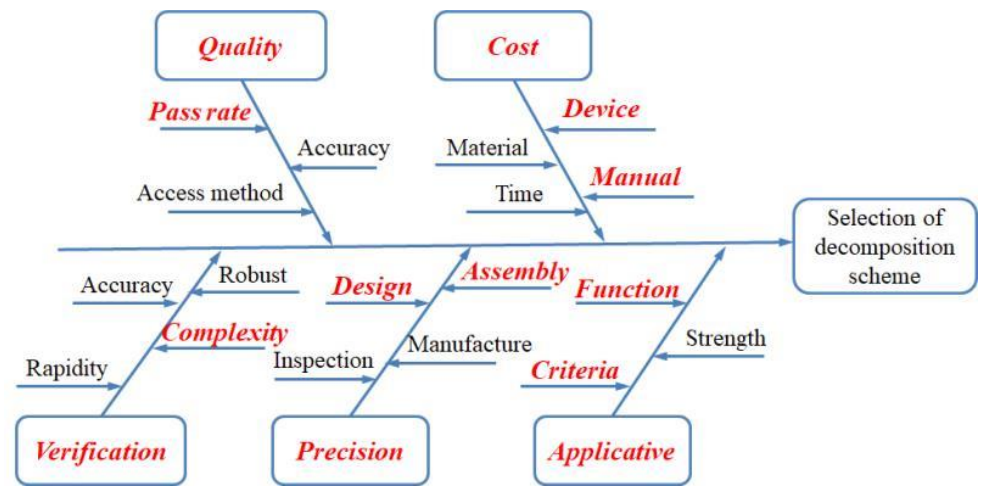

Fig. 3 The classification of dynamic factors

A static factor is an influential factor for the tolerancing specification, which is from the standard, rules, the geometrical relationship (see Table 1). Designers usually cannot change the weight of static factors. In this context, the static factors are geometrical type, position relationship with DRF and assembly relationship. The geometrical type could determine the candidate tolerances for a feature (see an example in Table 7); the position relationship with DRF could affect the selection of orientation and positioning tolerances; the assembly relationship determines the features that need to be specified.

\subsection{The MADM method}

As shown in Fig. 2, the input of the MADM method are both static factors (via some preprocessed) and dynamic factors, and output is the selected optimal scheme which will be used by $\mathrm{AD}$ algorithm. The MADM method is used to help the engineer to make decisions on the alternatives (i.e. different candidate schemes produced by static factors) according to their preferences in the form of dynamics factors. Fig. 4 illustrates the diagram of the MADM algorithm, which is consist of five steps. 


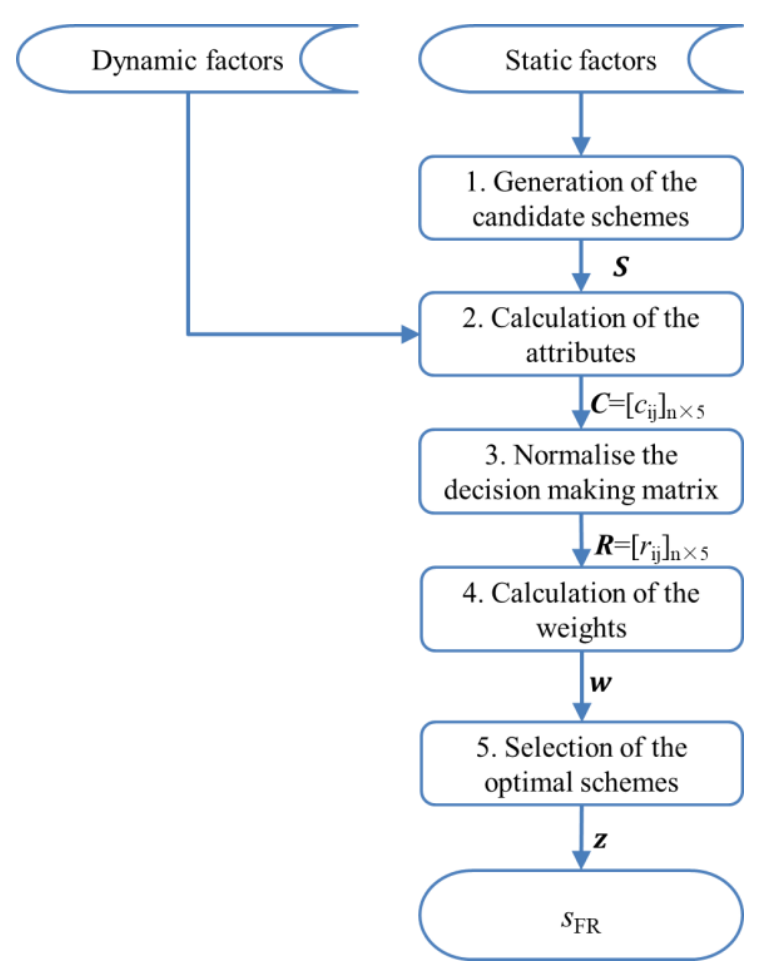

Fig. 4 The diagram of the MADM algorithm

\section{Step 1: Generation of the candidate schemes}

The first step is to generate the candidate schemes set $\boldsymbol{S}$ from the input, i.e. the static factors of a feature on a workpiece. A feature can be an integral feature or a derived feature. And the feature is described by the candidate schemes set $\boldsymbol{S}$ after this operation.

The geometric tolerance (e.g. roundness) is represented as a $D P$ (see Table 7 which is DPs for all geometric tolerances defined in ISO 1101:2017). A feature (e.g. a sphere) will be decomposed to the basic elements (i.e. DPs as shown in Table 8 which listed candidate tolerance for different features based on TTRS), together with the essential reference (i.e. datum). The purpose of decomposition is to find all possible FRs (namely the candidate schemes set $\boldsymbol{S}$ in this context) for a feature (i.e. $\boldsymbol{S}$ as shown in Table 9 are the possible sets for different features). This operation is detailed in Appendix 1.

Step 2: Calculation of the attribute values

If the output of step 1 provides more than one $D P$, it becomes a selection problem with consideration of dynamic factors. A dynamic factor is modelled as an attribute $\boldsymbol{u}$ of each candidate scheme (i.e. $D P$ ) for further assessment. The Quality attribute, for example, is estimated by the pass rates based on the standard [36]. Assuming that the verification of each geometrical tolerance is independent of the others, the qualification rate $c_{i l}$ is

$$
c_{i 1}=u_{1}\left(s_{i}\right)=\prod_{k=1}^{i} \eta_{k}
$$

where the success rate of a single tolerance type inspection be $\eta_{k}$, the number of tolerances is $i$ $(i=1, \ldots, n)$.

Then, the attribute value of each scheme is calculated by $c_{i j}=u_{j}\left(s_{i}\right)$., which could be represented as $\boldsymbol{C}=\boldsymbol{U}(\boldsymbol{S})$, where the attributes models $u_{j}$ () could be estimated (see Table 10). For example, the decision-making matrix of the feature $f_{2}$ in Fig. 6 is calculated as Eq. (4).

$$
\boldsymbol{C}=\boldsymbol{U}(\boldsymbol{S})=\left[\begin{array}{ccc}
u_{1}\left(s_{1}\right) & \ldots & u_{5}\left(s_{1}\right) \\
\vdots & \ddots & \vdots \\
u_{1}\left(s_{5}\right) & \ldots & u_{5}\left(s_{5}\right)
\end{array}\right]
$$


Step 3: Normalisation of the decision-making matrix

In this step, the attributes are normalised to $[0,1]$ via Eq. (5) and Eq. (6) as follows.

$$
\begin{gathered}
c_{i 1}: r_{i 1}=\frac{c_{i 1}}{\max \left\{c_{i 1}, i=1, \ldots, n\right\}} \\
c_{i 2}, c_{i 3}, c_{i 4}, \text { and } c_{i 5}: r_{i j}=\frac{\min \left\{c_{i j}, i=1, \ldots, n\right\}}{c_{i j}}
\end{gathered}
$$

Then, attributes matrix $\boldsymbol{R}=\left[r_{\mathrm{ij}}\right]_{\mathrm{n} \times 5}$ is obtained.

Step 4: Calculation of the weights

The significance of each attribute is assessed by entropy algorithm adopted from [44]. The entropy $\boldsymbol{E}=\left[E_{1}, E_{2}, \ldots, E_{5}\right]^{T}$ of each attribute is calculated as:

$$
\begin{gathered}
E_{j}=-\frac{1}{\operatorname{logn}} \sum_{i=1}^{n} \bar{r}_{i j} \log \bar{r}_{i j}, j=1,2, \ldots, 5 \\
\text { where } \bar{r}_{i j}=\frac{r_{i j}}{\sum_{i=1}^{n} r_{i j}}, i=1,2, \ldots, n, j=1,2, \ldots, 5
\end{gathered}
$$

if $\bar{r}_{i j}=0$, then $\bar{r}_{i j} \log \bar{r}_{i j}=0$.

The weight $\boldsymbol{w}=\left[w_{1}, w_{2}, w_{3}, w_{4}, w_{5}\right]^{\mathrm{T}}$ is calculated as:

$$
w_{j}=\frac{1-E_{j}}{\sum_{k=1}^{5}\left(1-E_{k}\right)}, j=1,2, \ldots, 5
$$

Step 5: Selection of the optimised schemes

The evaluation vector $\boldsymbol{z}=\left[z_{1}, z_{2}, \ldots, z_{n}\right]^{T}$ is calculated as:

$$
\boldsymbol{z}=\boldsymbol{R} \boldsymbol{w}
$$

Let $z_{i}=\max \left(z_{1}, z_{2}, \ldots, z_{n}\right)$, then $s_{F R}=s_{i}$. Thus, the optimal decomposition scheme $s_{F R}$ is obtained.

\subsection{The generation of geometrical tolerances by AD algorithm}

As shown in Fig. 2, $s_{F R}$ and $D P$ s will be processed by the AD algorithm to generate the geometrical tolerances. More detail of the AD algorithm can be found in [30]. Fig. 5 shows the information flow of the AD algorithm. The selected scheme $s_{F R}$ is decomposed (see Appendix A) into a set of FRs which represent the variations of form, orientation and translation. Then, $s_{F R}$ and $D P s$ is evaluated by the $\mathrm{AD}$ algorithm to select geometrical tolerance for the feature.

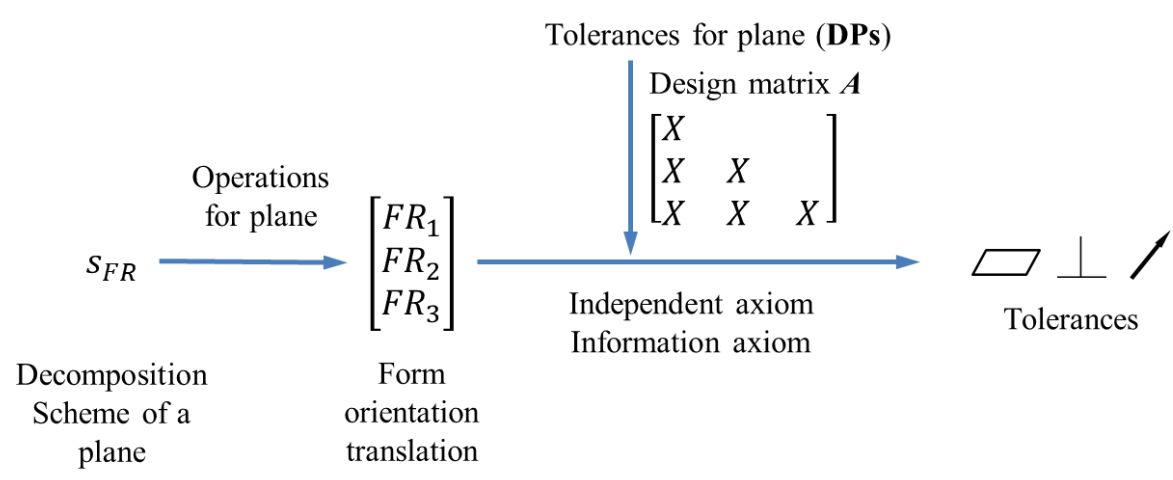

Fig. 5 The generation of the tolerances for a plane feature

In this algorithm, two axioms are used in operations: 1) the independent axiom requires each selected $D P$ to satisfy each $F R$ independently or decoupling, which means the selected $D P$ s should make the design matrix $\boldsymbol{A}$ independent and decouple; 2) the information axiom requires the information of using $D P$ is the least in candidate $D P$ s. The information value of each $D P$ is 
calculated. For example, $D P_{\mathrm{i}}$ in Table 7 is assessed as

$$
I_{i}=I_{d}+I_{c i}+I_{p}+I_{m}=I_{d}+\log _{2} \frac{c_{i}}{c_{\min }}+\log _{2} \frac{P_{s y s}}{V}+\log _{2} \frac{3 m_{s y s}}{V}, i=1, \ldots, 15
$$

where $I_{d}, I_{c i}, I_{p}, I_{m}$ are the information value of the datum, cost, process and inspection respectively; $c_{i}$ is the relative cost and $c_{\min }$ is the least cost in the same class; $V$ is the estimated value of $F R_{1}, F R_{2}$ or $F R_{3} ; P_{s y s}$ is the process precision; $m_{s y s}$ is the measuring precision.

Fig. 6 shows an example which needs to specify feature $f_{1}$, a plane with two datums. $f_{1}$ is decomposed to $F R_{1}, F R_{2}$ and $F R_{3}$, and the decomposition scheme for feature $\mathrm{f}_{1}$ is $s_{\mathrm{p} 3}$. According to Eq. (2) and the independent axiom, a form tolerance, an orientation tolerance and a positioning tolerance are applied to control the variation of feature $f_{1}$. It will obtain a design matrix A with decouple form as:

$$
\boldsymbol{A}=\left[\begin{array}{lll}
X & & \\
X & X & \\
X & X & X
\end{array}\right]
$$

Assume that the other conditions are the same to the case study, the comparison (see in Table 13) shows the $D P_{2}(\square), D P_{6}(\perp)$ and $D P_{I l}(/)$ are applied to specify feature $f_{1}$. Therefore, the flatness, perpendicularity and circular runout are selected to specify feature $f_{1}$.

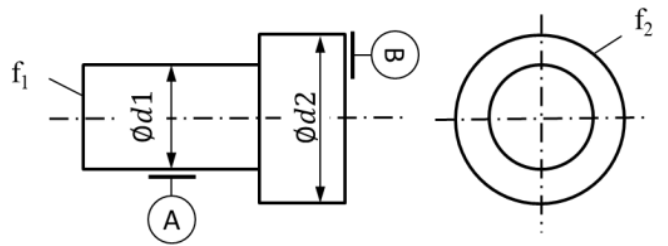

Fig. 6 An example of features to be specified, $f_{1}$ is a plane and $f_{2}$ is a cylinder surface.

\section{Case study}

\subsection{Tolerance specification of a cycloidal}

A typical part, a cycloidal gear of an RV reducer, is selected to demonstrate the use of the MADM method to tolerance specification. This part is consist of features defined in ISO 1101:2017. Fig. 7 illustrates the structure of the RV reducer, which includes two cycloidal gears. Fig. 8 is the drawing of the gear. In this case, the input data is listed in Table 3 and Table 12. Table 3 is generated according to the CAD model of the product. Table 12 is obtained based on an investigation in a factory. Tables are stored in an Excel file. Algorithms are developed in Matlab. 


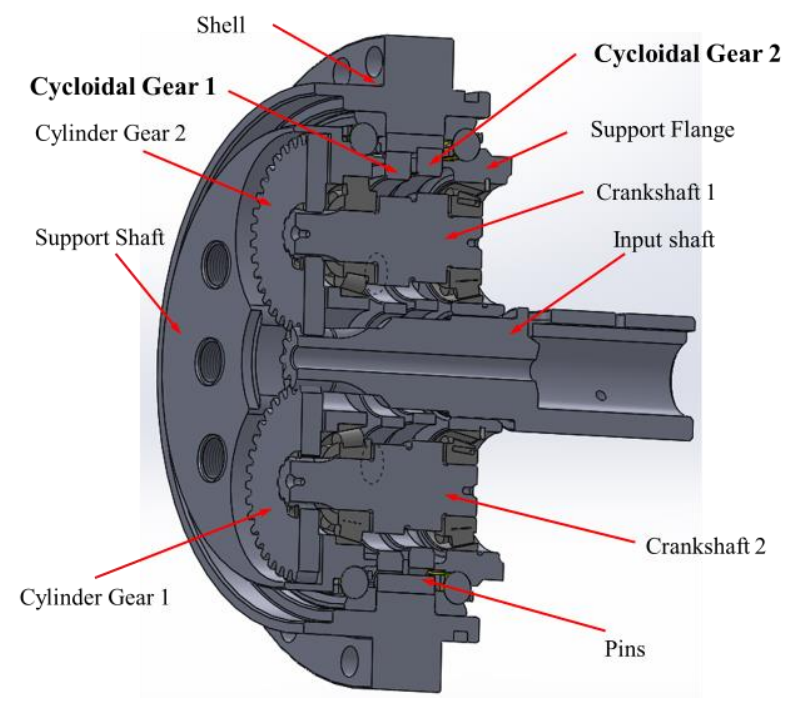

Fig. 7 Structure of the RV reducer

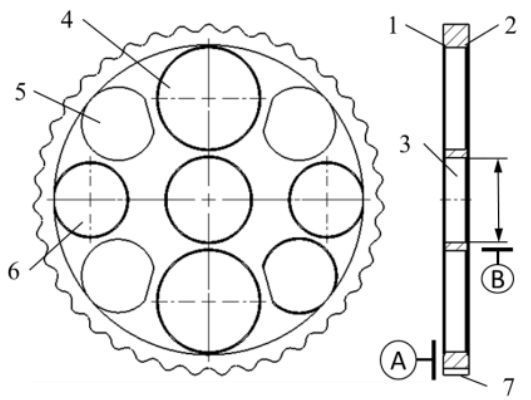

Fig. 8 Drawing of a cycloidal gear

Feature 2 on the gear is selected to shows the data flow of tolerance specification (see Fig. 9). Firstly, the DRF is established by the MGDE-based algorithm. In this case, the primary datum is Feature 1, and the secondary datum is Feature 3. Seven features on the gear are selected to develop specified tolerance. Fig. 8 illustrated the results of the DRF selection. Secondly, the static factors of each feature are analysed, and their candidate scheme sets DPs is generated. Table 3 shows the results. Thirdly, the MADM algorithm evaluates the dynamic factors (listed in Table 13) and DPs (see Table 9). It calculates the decision-making matrix $\boldsymbol{C}$ (see Eq. (4), Table 10 and Table 11), $\boldsymbol{R}$ (see Eq. (5 6)), $\boldsymbol{w}$ (see Eq. (7 9)) and $\boldsymbol{z}$ (see Eq. (10)). Thus, the optimal scheme $s_{F R}$ is obtained according to $z$. Fourthly, AD algorithm assesses the $s_{F R}$ and DPs (see Table 8) by independent axiom and Eq. (11) (parameters are illustrated in Table 13). Finally, tolerance is selected. For example, the algorithm selects position tolerance and flatness tolerance for feature 2. The optimised schemes for other features of the cycloidal gear are selected, and the results are listed in Table 4. The tolerance specification results for the cycloidal gear are illustrated in

Table 5 and Fig. 10. They are adhered to the ISO standard [25], and satisfy the requirements of TTRS.

Table 3 The static factors of each feature

\begin{tabular}{ccccc}
\hline Feature & Geometrical type & $\begin{array}{c}\text { Position relation with } \\
\text { primary datum }\end{array}$ & $\begin{array}{c}\text { Assembly } \\
\text { relationship }\end{array}$ & $\begin{array}{c}\text { Candidate Scheme } \\
\text { Set }\end{array}$ \\
\hline 1 & Plane & Primary datum & Supporting & $\boldsymbol{S}_{\boldsymbol{p}}=\left[s_{p 1}\right]$ \\
& & flange & \\
2 & Plane & Parallel & Shim & $\boldsymbol{S}_{\boldsymbol{p}}=\left[s_{p 1}, s_{p 2}, s_{p 3}\right]$ \\
\hline
\end{tabular}




\begin{tabular}{ccccc}
\hline 3 & $\begin{array}{c}\text { Revolving feature } \\
\text { (Cylinder) }\end{array}$ & $\begin{array}{c}\text { Perpendicular } \\
\text { (Secondary datum) }\end{array}$ & Input shaft & $\boldsymbol{S}_{\boldsymbol{r}}=\left[s_{\mathrm{r} 1}, s_{\mathrm{r} 2}\right]$ \\
4 & Pattern & Perpendicular & Bearing & $\boldsymbol{S}_{\boldsymbol{z}}=\left[s_{z 1}, s_{z 2}, s_{z 3}\right]$ \\
5 & Pattern & Perpendicular & Pin & $\boldsymbol{S}_{\boldsymbol{z}}=\left[s_{z 1}, s_{z 2}, s_{z 3}\right]$ \\
6 & Pattern & Perpendicular & Pin & $\boldsymbol{S}_{\boldsymbol{z}}=\left[s_{z 1}, s_{z 2}, s_{z 3}\right]$ \\
7 & Gear & Perpendicular & Gear & $/$ \\
\hline
\end{tabular}

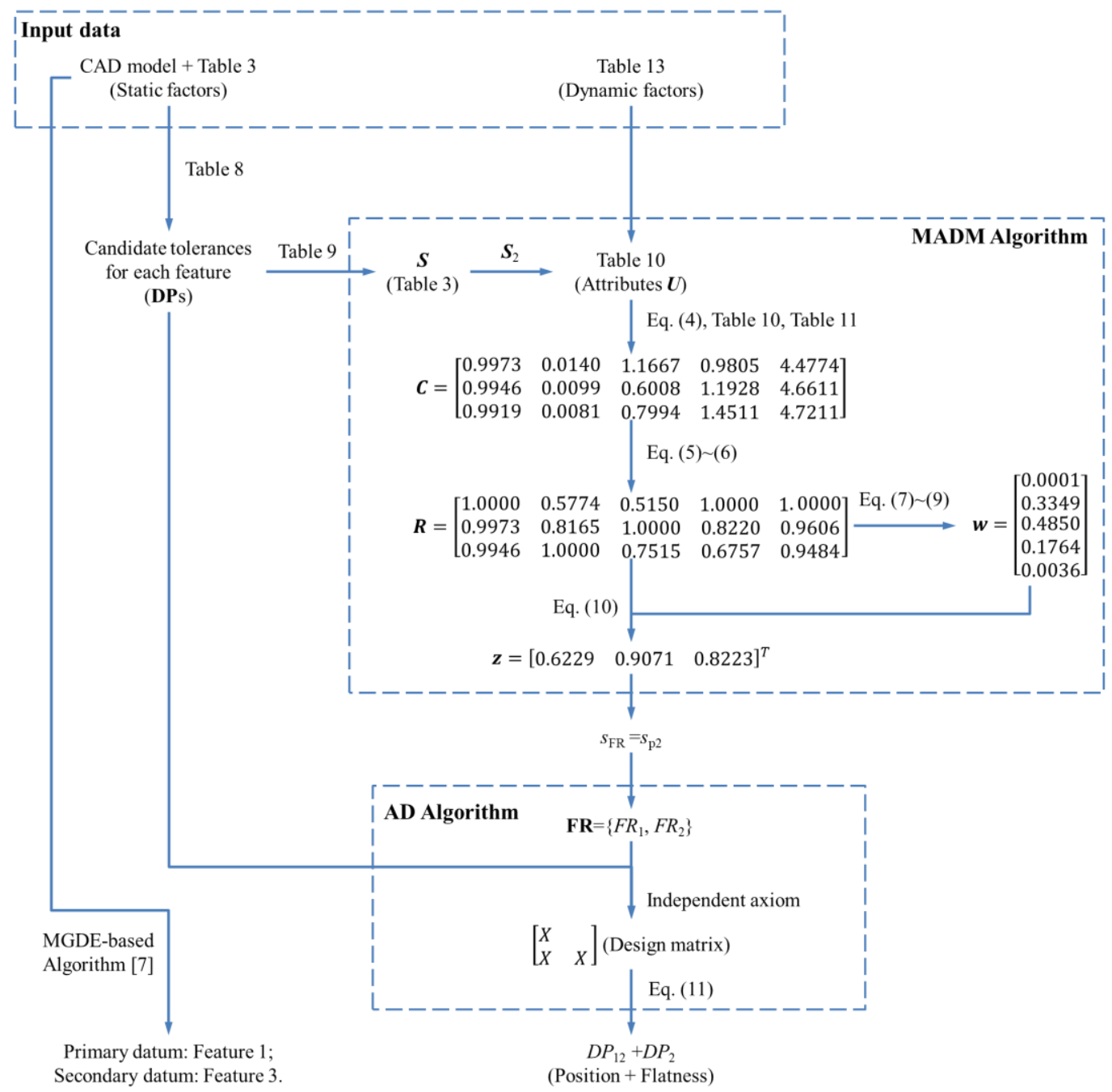

Fig. 9 Data flow of tolerance specification for feature 2 of the cycloidal gear

Table 4 The optimised decomposition scheme of each feature

\begin{tabular}{ccccccc}
\hline Feature & 1 & 2 & 3 & 4 & 5 & 6 \\
\hline$d / \mathrm{mm}$ & 112 & 112 & 33 & 75 & 85 & 85 \\
Types & Plane & Plane & Cylinder & Pattern & Pattern & Pattern \\
schemes & $s_{p 1}$ & $s_{p 2}$ & $s_{r 2}$ & $s_{z 2}$ & $s_{z 1}$ & $s_{\mathrm{z} 1}$ \\
\hline
\end{tabular}

Table 5 The tolerance specification results of the cycloidal gear

\begin{tabular}{ccc}
\hline No. & Feature Type & Tolerancing results \\
\hline cg-1 & Plane & $D P_{2}(\square)$ \\
cg-2 & Plane & $D P_{12}(\phi)+D P_{2}(\square)$
\end{tabular}




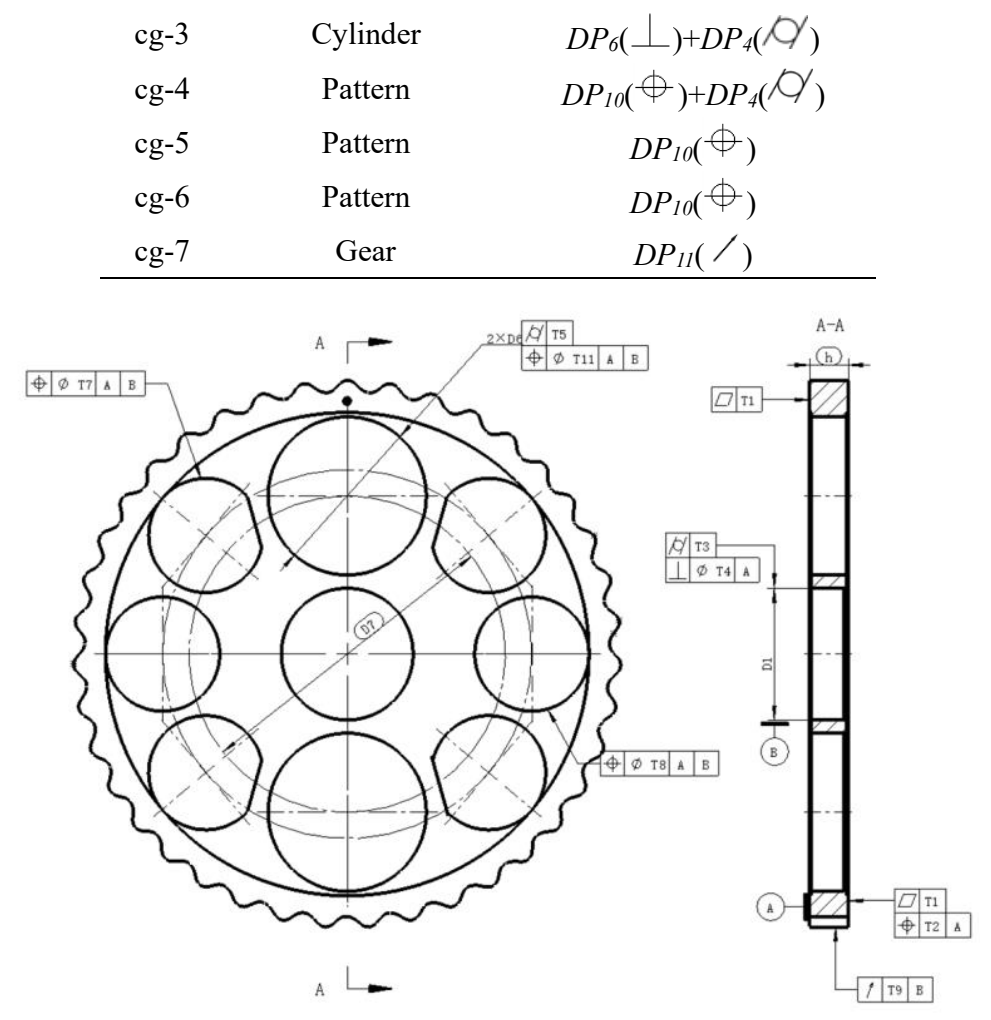

Fig. 10 The tolerance specification results of the cycloidal gear on the precision requirement of IT5

\subsection{Discussion}

This case study shows the dynamic factors can be used to select the tolerance specification scheme. Traditionally, the selection is based on the experience of the engineer. Dynamic factors model the preference as a set of attributes in the selection process. Five dynamic factors were defined and used to describe the preference. It provides a solution to store the expert's knowledge in the selection of the tolerance scheme.

The factors, usually conflicting, are quantified by their weight. The outcome could be varied for different preference. For example, a designer decides to upgrade the precision requirement (from the IT5 to IT6) on the gear shown in Fig. 8. The developed MADM algorithm undertook a reassessment. Table 6 lists the optimised schemes and Fig. 11 illustrates the tolerance specification. It shows that more geometrical tolerances are selected to control feature 2 and feature 4 . Thus, the developed MADM algorithm made a different selection for different preference. Furthermore, it also illustrates the effect of the dynamic factors for the tolerance specification.

Table 6 The optimised decomposition scheme of each feature with different precision requirements

\begin{tabular}{ccccccc}
\hline Feature & 1 & 2 & 3 & 4 & 5 & 6 \\
\hline$d / \mathrm{mm}$ & 112 & 112 & 33 & 75 & 85 & 85 \\
Types & Plane & Plane & Cylinder & Pattern & Pattern & Pattern \\
Schemes (IT 6) & $s_{p 1}$ & $s_{p 2}$ & $s_{r 2}$ & $s_{z 2}$ & $s_{z 1}$ & $s_{\mathrm{z} 1}$ \\
Schemes (IT 5) & $s_{p 1}$ & $s_{p 3}$ & $s_{r 2}$ & $s_{z 3}$ & $s_{z 1}$ & $s_{\mathrm{z} 1}$ \\
\hline
\end{tabular}




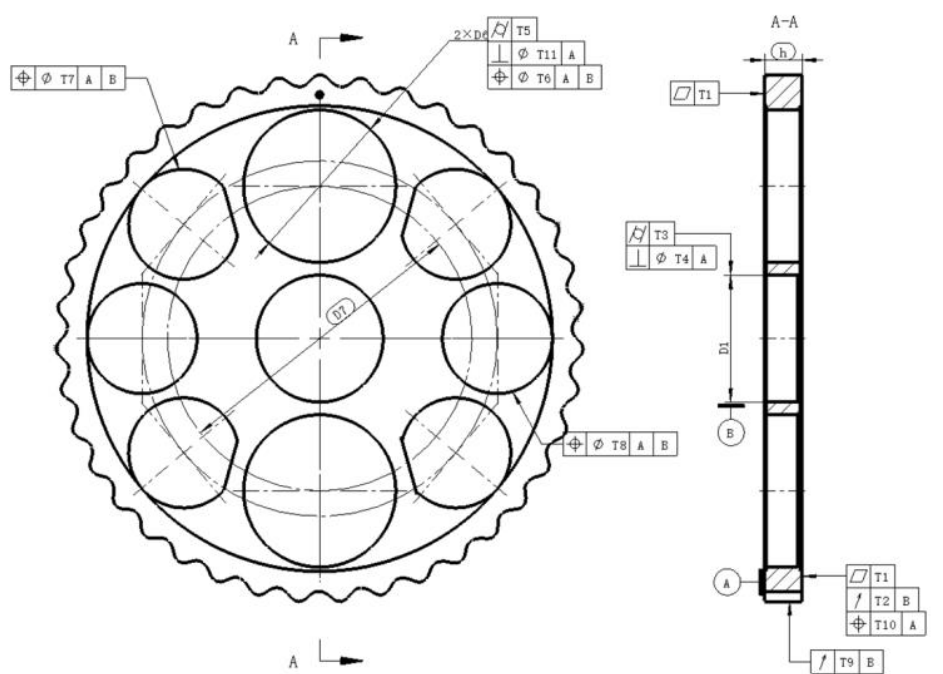

Fig. 11 The tolerance specification results of the cycloidal gear on the precision requirement of IT6

The developed MADM algorithm is employed to assess five dynamics factors only, and it should be able to deal with more factors/sub-factors according to the use of MADM method in other fields [31]. AD method was introduced in the assessment of the flatness [30]. However, it cannot be used directly to develop tolerance with DRF. Now, the AD method can select tolerance with DRF when using it with the MADM algorithm. Thus, the MADM method extends the usage of the AD method in the Computer-Aided Tolerance design.

\section{Conclusion and future work}

In this paper, the MADM method is introduced and applied on computer-aided tolerance specification. This new method is not only considering the factors used in the traditional methods but also including the influential factors varied according to the work floor situation. The dynamic factors are analysed and grouped to describe the preference of engineers. Those factors were handled by the developed MADM algorithm, together with the rule-based algorithm and AD algorithm. A case study was undertaken. The results show that the developed algorithms generate the specification which is adhered to ISO standard and compatible with the requirements of TTRS.

This paper has made two contributions to this field, that of the assessment of the dynamic factors via computer algorithms, and that of the introduce of MADM method. This method is relatively complicated, which reflect the situation in the manufacturing site. Further development will be undertaken in future, that of a study and verification work of the estimation of the attributes, and that of a reliable verification method to access tolerance specification.

\section{Acknowledgements}

This research was supported by the National Natural Science Foundation of China (No. 51575484 and U1501248) and Science Fund for Creative Research Groups of the National Natural Science Foundation of China (No. 51521064). The authors would also like to acknowledge the supports by the EPSRC Future Advanced Metrology Hub (Ref. EP/P006930/1). 


\section{Reference:}

1. Goetz, S., Schleich, B., \& Wartzack, S. (2018). A new approach to first tolerance evaluations in the conceptual design stage based on tolerance graphs. Procedia CIRP, 75, 167-172. doi:10.1016/j.procir.2018.04.030.

2. Hong, Y. S., \& Chang, T. C. (2002). A comprehensive review of tolerancing research. International Journal of Production Research, 40(11), 2425-2459. doi:10.1080/00207540210128242.

3. Hallmann, M., Schleich, B. \& Wartzack, S. (2020). Form tolerance allocation to tolerance-cost optimisation: a comprehensive literature review. Int J Adv Manuf Technol 107, 4859-4912. https://doi.org/10.1007/s00170020-05254-5.

4. M. C. Bianca, N. Senin. (2011). Geometric Tolerances. Springer, London.

5. T. Wang. (2013). The foundation and application of GD\&T., China Machine Press, Beijing.

6. Dantan, J., Mathieu, L., Ballu, A., \& Martin, P. (2005). Tolerance synthesis: Quantifier notion and virtual boundary. Computer-Aided Design, 37(2), 231-240. doi:10.1016/j.cad.2004.06.008.

7. Desrochers, A., Clément, A. (1994). A dimensioning and tolerancing assistance model for CAD/CAM systems. Int J Adv Manuf Technol 9, 352-361. https://doi.org/10.1007/BF01748479.

8. Clement A, Riviere A, Serre P, Valade C. (1997). The TTRS: 13 Constraints for Dimensioning and Tolerancing. Proceedings of the 5th CIRP International Seminar on Computer-Aided Tolerancing..pp:73-82.

9. Salomons, O. W., Poerink, H. J. J., Haalboom, F. J., van Slooten, F., van Houten, F. J. A. M., \& Kals, H. J. J. (1996). A computer aided tolerancing tool I: Tolerance specification. Computers in Industry, 31(2), 161-174. doi:10.1016/0166-3615(96)00046-2.

10. D. Gaunet. (2003). 3D functional tolerancing \& annotation: CATIA tools for geometrical product specification. Geometric Product Specification and Verification: Integration of Functionality. Springer, Dordrecht. pp: 2533.

11. Hu, J., Xiong, G., \& Wu, Z. (2004). A variational geometric constraints network for a tolerance types specification. The International Journal of Advanced Manufacturing Technology, 24(3), 214-222. doi:10.1007/s00170-003-1572-7.

12. Zhang, Y., Li, Z., Gao, J., \& Hong, J. (2011). New reasoning algorithm for assembly tolerance specifications and corresponding tolerance zone types. Computer-Aided Design, 43(12), 1606-1628. doi:10.1016/j.cad.2011.06.008.

13. Zhong, Y., Qin, Y., Huang, M., Lu, W., Gao, W., \& Du, Y. (2013). Automatically generating assembly tolerance types with an ontology-based approach. Computer Aided Design, 45(11), 1253-1275. doi:10.1016/j.cad.2013.06.006.

14. Qin, Y., Zhong, Y., Huang, M., \& Liu, F. (2014). An assembly tolerance representation model based on spatial relations for generating assembly tolerance types. Proceedings of the Institution of Mechanical Engineers, Part C: Journal of Mechanical Engineering Science, 228(6), 1005-1020. doi:10.1177/0954406213495501.

15. Y. Qie, L. Qiao, Y. Cui \& N. Anwer. (2017). A Domain Ontology for Assembly Tolerance Design. Proc. ASME. IMECE2017, Volume 2: Advanced Manufacturing, V002T02A112, November 3-9, 2017.

16. Anselmetti, B., \& Mawussi, K. (2003). Computer aided tolerancing using positioning features. Journal of Computing and Information Science in Engineering, 3(1), 15-21. doi:10.1115/1.1565074.

17. Anselmetti, B. (2006). Generation of functional tolerancing based on positioning features. Computer Aided Design, 38(8), 902-919. doi:10.1016/j.cad.2006.05.005.

18. Anselmetti, B., Chavanne, R., Yang, J., \& Anwer, N. (2010). Quick GPS: A new CAT system for single-part tolerancing. Computer-Aided Design, 42(9), 768-780. doi:10.1016/j.cad.2010.04.006.

19. Cao, Y., Zhang, H., Li, B., Wu, Z., \& Yang, J. (2013). Study on functional specification scheme on interface 
based on positioning features. Proceedings of the Institution of Mechanical Engineers, Part B: Journal of Engineering Manufacture, 227(5), 745-753. doi:10.1177/0954405413479112.

20. Qin, Y., Lu, W., Qi, Q., Liu, X., Huang, M., Scott, P. J., \& Jiang, X. (2018). Towards a tolerance representation model for generating tolerance specification schemes and corresponding tolerance zones. The International Journal of Advanced Manufacturing Technology, 97(5), 1801-1821. doi:10.1007/s00170-018-1977-y.

21. P. Haghighi, P. Mohan, N. Kalish, P. Vemulapalli, J. J. Shah, \& J. K. Davidson. (2015). Toward Automatic Tolerancing of Mechanical Assemblies: First-Order GD\&T Schema Development and Tolerance Allocation. Journal of Computing and Information Science in Engineering. 15(4), 041003-041003-9.

22. Antonio Armillotta. (2013). A method for computer-aided specification of geometric tolerances. ComputerAided Design. 45, 1604-1616.

23. Y. Cao, Q. Zhao, T. Liu, L. Ren, \& J. Yang. (2018). The Strategy of Datum Reference Frame Selection Based on Statistical Learning. Journal of Computing and Information Science in Engineering. 18(2):021002-0210029.

24. Qin, Y., Lu, W., Qi, Q., Liu, X., Huang, M., Scott, P. J., \& Jiang, X. (2018). Towards an ontology-supported case-based reasoning approach for computer-aided tolerance specification. Knowledge-Based Systems, 141, 129-147. doi:10.1016/j.knosys.2017.11.013.

25. ISO 1101:2017. Geneva: International Organization for Standardization. 2017.

26. ASME Y14.5 2018, Dimensioning and Tolerancing. ASME, New York. 2018.

27. N. P. Suh. (1978). Optimisation of Manufacturing Systems through Axiomatics. CIRP Annals. 27(1), 383-388.

28. M. C. Bahadir \& S.I. Satoglu. (2014). A novel robot arm selection methodology based on axiomatic design principles. International Journal of Advanced Manufacturing Technology. 71, 2043-2057.

29. S. J. Lee \& G. J. Park. (2014). A novel method of reverse engineering using axiomatic design. Journal of Mechanical Science and Technology. 28(2):595-604.

30. Q. Zhao, Y. Cao, T. Liu, L. Ren, J. Yang. (2018). Tolerance Specification of the Plane Feature Based on the Axiomatic Design. Proceedings of the Institution of Mechanical Engineers, Part C: Journal of Mechanical Engineering Science, doi:10.1177/0954406218772001.

31. Hwang C. L., Yoon K. (2012). Multiple Attribute Decision Making: Methods and Applications: A State-of-theArt Survey. Springer Science \& Business Media. London.

32. Li, C., Zhang, X., Geng, H., \& Yan, J. (2017). Robustness analysis model for MADM methods based on cloud model. Procedia Computer Science, 107, 84-90. doi:10.1016/j.procs.2017.03.061.

33. M.A. Kashfi, \& M. Javadi. (2015). A model for selecting suitable dispatching rule in FMS based on fuzzy multi attribute group decision-making. Production Engineering-Research and Development. 9, 237-246.

34. J. Xiangqian. (2007). Theory and Applications of New Generation Geometrical Product Specifications. Higher Education Press. Beijing.

35. Segal, S., \& Gurfil, P. (2009). Effect of kinematic rotation-translation coupling on relative spacecraft translational dynamics. J Guid Control Dynam, 32(3), 1045-1050. doi:10.2514/1.39320.

36. ISO 14253-2:2017. International Organization for Standardization. Geneva.2017.

37. Li, G., He, S., Ju, Y., \& Du, K. (2014). Long-distance precision inspection method for bridge cracks with image processing. Automation in Construction, 41, 83-95. doi:10.1016/j.autcon.2013.10.021.

38. ISO 286-2. International Organization for Standardization. Geneva.2017.

39. Dornfeld D, \& Lee D E. (2008). Machine design for precision manufacturing. Springer. New York.

40. Cao, Y., Liu, T., \& Yang, J. (2018). A comprehensive review of tolerance analysis models. International Journal of Advanced Manufacturing Technology, 97(5-8), 3055-3085. doi:10.1007/s00170-018-1920-2.

41. Z Wu, \& J. Yang. (1999). Computer Aided tolerance optimised design. Zhejiang University Press. Hangzhou. 
42. Armillotta, A. (2020). Selection of parameters in cost-tolerance functions: review and approach. Int J Adv Manuf Technol 108, 167-182. https://doi.org/10.1007/s00170-020-05400-z.

43. C.L. Hwang, K Yoon. (1981). Multiple Attribute Decision-making and Applications. Springer-Verlag, New York.

44. H. Zhang, L. Yu. (2012). MADM method based on cross-entropy and extended TOPSIS with interval-valued intuitionistic fuzzy sets. Knowledge-Based Systems. 30, 115-120.

45. B. Farhadinia. (2016). Determination of entropy measures for the ordinal scale-based linguistic models. Information Sciences. 369, 63-79.

46. Q. Zhao, L. Ren. (2017). A survey for the production condition of the Shaoxing Advance Gearbox Co., Ltd. (unpublished, in Chinese).

47. C. Kong, J. Wang, T. Li. (2019) A Survey of Engineering Education of Geometrical Product Specifications and Verification in China. (To be published in ICAC). 


\section{Appendix 1: Decomposition operation for a feature}

The variation of a feature is considered as a combination of one/several types of variations in tolerance specification. In this context, decomposition refers to an operation to separate those variations into the variations of translation, rotation and form. In this paper, the decomposition is developed based on the kinematics [35] and the geometrical characteristics of the feature. An example of this operation is illustrated in Fig. 12. The tolerances can control variations decoupling by this decomposition method. According to the definition of each geometric tolerance, a positioning tolerance controls three variations; an orientation tolerance controls rotation variation and form variation [34]; a form tolerance only controls form variation (see Fig. 12). In this case, a plane could be decomposed to one, two or three variations and noted as $s_{p 1}, s_{p 2}$ and $s_{p 3}$ respectively.

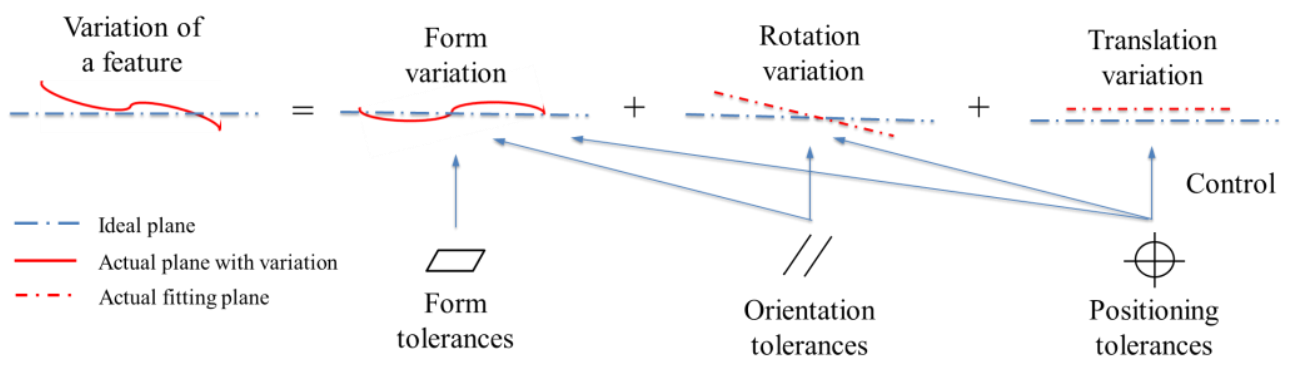

Fig. 12 Decomposition operation on a plane, viewed from the direction paralleled to the plane.

Some features are consist of a derive feature with an integral feature, which the decomposition has more than one results. Rule $\mathbf{1}$ and Rule $\mathbf{2}$ is supplied in order to provide unambiguous results.

Rule 1: If a feature has derived feature(s), then (1) the rotation and translation variation of a feature are controlled through its derived feature first, and (2) the form variation of a feature is controlled through its integral feature.

For example, the variations of a cylinder are decomposed to the positioning variation of its axis, the rotation variation of its axis, the form variation of its axis, the axial variation of integral feature and the radial variation of an integral feature. It means that the number of variations of a cylinder could be $1,2,3,4$ or 5 .

Rule 2: If a feature is a primary datum, its rotation and translation variation are not considered; if a feature is a secondary datum, its positioning variation is not considered.

A decomposition scheme is a result of the decomposition, e.g. "decompose to kinematic and form variation". A candidate schemes set $\boldsymbol{S}$ is a group of the decomposition schemes of a feature. The candidate tolerances, geometric type of feature and position relationship with DRF are applied to generate the $\boldsymbol{S}$.

\section{Appendix 2: The tables of DPs, candidate tolerances, candidate}

\section{schemes set and estimation of attributes}

Table 7 DPs for all geometric tolerances (adopt from [25])

\begin{tabular}{ccccc}
\hline DPs $^{1}$ & Geometric tolerance & Symbol & $\begin{array}{c}\text { The requirement of } \\
\text { datum }\end{array}$ & Tolerance type \\
\hline$D P_{I}$ & Straightness & - & No & Form \\
\hline
\end{tabular}




\begin{tabular}{|c|c|c|c|c|}
\hline $\mathrm{DP}_{2}$ & Flatness & $\square$ & No & Form \\
\hline $\mathrm{DP}_{3}$ & Roundness & O & No & Form \\
\hline $\mathrm{DP}_{4}$ & Cylindricity & d & No & Form \\
\hline$D P_{5}$ & Parallelism & // & Yes & Orientation \\
\hline$D P_{6}$ & Perpendicularity & $\perp$ & Yes & Orientation \\
\hline$D P_{7}$ & Angularity & $<$ & Yes & Orientation \\
\hline$D_{8}$ & Coaxiality & (2) & Yes & Positioning \\
\hline$D P_{9}$ & Symmetry & $\equiv$ & Yes & Positioning \\
\hline$D P_{10}$ & Position & $\phi$ & Yes & Positioning \\
\hline$D P_{11}$ & Circular Runout $^{1}$ & I & Yes & Positioning \\
\hline$D P_{12}$ & Total Runout $^{1}$ & $\angle$ & Yes & Positioning \\
\hline$D P_{13}$ & Concentricity & (a) & Yes & Positioning \\
\hline$D P_{14}$ & Line Profile ${ }^{2}$ & $\frown$ & Yes/No & / \\
\hline$D P_{15}$ & Surface Profile ${ }^{2}$ & $\bigcirc$ & Yes/No & l \\
\hline
\end{tabular}

${ }^{1}$ The circular and total runout determines the position, so they are classified as position tolerance.

${ }^{2}$ Line and surface profile can be used as form, orientation or position tolerance, so the datum requirement is dynamic.

Table 8 The candidate tolerances for different features

\begin{tabular}{|c|c|}
\hline Geometrical Type & Candidate geometrical tolerances \\
\hline Plane $^{1}$ & $\begin{array}{c}D P_{1}(-), D P_{2}(\square), D P_{5}(/ /), D P_{6}(\perp), D P_{7}(\measuredangle), D P_{9}(\overline{=}) \\
D P_{10}(\phi), D P_{11}(/) \text { or } D P_{12}(\llcorner)\end{array}$ \\
\hline Revolving surface ${ }^{1}$ & 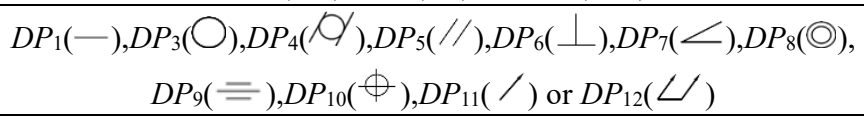 \\
\hline Sphere $^{1}$ & $D P_{3}(\bigcirc)$ and $D P_{13}(\bigcirc)$; or $D P_{10}(\phi)$ \\
\hline Pattern $^{1}$ & $D P_{1}(-) / D P_{4}\left(Q^{\prime}\right)^{3}, D P_{5}(/ /), D P_{6}(\perp), D P_{7}(\angle), D P_{10}(\phi)$ \\
\hline Key Slot/Multiple & Axial: $D P_{9}(\phi)$ \\
\hline keys $^{2}$ & Radial: $D P_{11}(/)$ \\
\hline Gear teeth $^{2}$ & $D P_{11}(/)$ \\
\hline Free curve $^{2}$ & $D P_{14}(\cap)$ \\
\hline Freeform surface $^{2}$ & $D P_{15}(\bigcirc)$ \\
\hline
\end{tabular}

Note: ${ }^{1}$ The candidate geometrical tolerances is bigger than one, and the selection will be continued. For example, the geometrical type of plane, there are nine possible geometrical tolerances (see Table 8).

${ }^{2}$ The candidate geometrical tolerance is equal to one, and the selection is made as there is only one result (i.e. no selection needed).

${ }^{3}$ The use of $D P_{1}(-)$ or $\mathrm{DP}_{4}(\mathrm{O} /)$ depends on the geometry type of each unit. If the unit is a cylinder, the $D P_{4}\left(C^{\prime}\right)$ is applied; otherwise, the $D P_{1}(-)$ is employed.

Table 9 The candidate schemes set for each type of feature

\begin{tabular}{ccc}
\hline Feature & Candidate schemes set & Notes \\
\hline Plane & Primary datum: $\boldsymbol{S}_{\boldsymbol{p}}=\left[s_{p 1}\right] ;$ & ${ }^{*}$ \\
& Secondary datum: $\boldsymbol{S}_{\boldsymbol{p}}=\left[s_{p 1}, s_{p 2}\right] ;$ & $s_{p 2}:$ To decomposition; \\
& Other cases: $\boldsymbol{S}_{\boldsymbol{p}}=\left[s_{p 1}, s_{p 2}, s_{p 3}\right]$. & $s_{p 3}:$ To decompose to kinematic and form variation; \\
\end{tabular}


variation.

\begin{tabular}{|c|c|c|}
\hline $\begin{array}{l}\text { Revolving } \\
\text { feature }\end{array}$ & $\begin{array}{c}\text { Primary datum: } \boldsymbol{S}_{\boldsymbol{r}}=\left[s_{\mathrm{r} 1}\right] ; \\
\text { Secondary datum: } \boldsymbol{S}_{\boldsymbol{r}}=\left[s_{\mathrm{r} 1}, s_{\mathrm{r} 2}\right] \text {; } \\
\text { Other cases: } \boldsymbol{S}_{\boldsymbol{r}}= \\
{\left[s_{\mathrm{r} 1}, s_{\mathrm{r} 2}, s_{r 3}, s_{\mathrm{r} 4}, s_{r 5}\right] .}\end{array}$ & $\begin{array}{c}s_{r 1}: \text { No decomposition; } \\
s_{r 2}: \text { To decompose to kinematic and form variation of the } \\
\text { derived feature; } \\
s_{r 3}: \text { To decompose to translation, rotation and form } \\
\text { variation of the derived feature; } \\
s_{r 4}: \text { To decompose to translation, rotation, central-line } \\
\text { variation and axial variation of integral feature. } \\
s_{r 5}: \text { To decompose to translation, rotation, central-line } \\
\text { variation, axial variation of integral feature and radial } \\
\text { variation of integral feature. }\end{array}$ \\
\hline Sphere & $\begin{array}{c}\text { Primary datum: } \boldsymbol{S}_{\boldsymbol{s}}=\left[s_{\mathrm{s} 1}\right] ; \\
\text { Secondary datum: } \boldsymbol{S}_{\boldsymbol{s}}=\left[s_{s 1}, s_{s 2}\right] \text {; } \\
\text { Other cases: } \boldsymbol{S}_{\boldsymbol{s}}=\left[s_{\mathrm{s} 1}, s_{\mathrm{s} 2}\right] .\end{array}$ & $\begin{array}{c}s_{\mathrm{s} 1}: \text { No decomposition; } \\
S_{\mathrm{s} 2}: \text { To decompose to translation and form variation. }\end{array}$ \\
\hline Pattern & $\begin{array}{c}\text { Primary datum: } \boldsymbol{S}_{\boldsymbol{z}}=\left[s_{\mathrm{z} 1}\right] ; \\
\text { Secondary datum: } \boldsymbol{S}_{\boldsymbol{z}}=\left[s_{z 1}, s_{z 2}\right] \text {; } \\
\text { Other cases: } \boldsymbol{S}_{\boldsymbol{z}}=\left[s_{z 1}, s_{z 2}, s_{z 3}\right] .\end{array}$ & $\begin{array}{c}s_{z 1}: \text { No decomposition; } \\
S_{z 2}: \text { To decompose to kinematic and form variation of the } \\
\text { derived feature; } \\
s_{z 3}: \text { To decompose to translation, rotation and form } \\
\text { variation of the derived feature. }\end{array}$ \\
\hline
\end{tabular}

*: It is unnecessary for further selection. 
Table 10 The description and estimation of the attributes

\begin{tabular}{|c|c|c|c|}
\hline Attributes & Symbol/Estimation & Description & Note \\
\hline Quality & $\begin{array}{c}c_{i 1}=u_{1}\left(s_{i}\right)=\prod_{k=1} \eta_{k} \\
(i=1,2, \ldots, n)^{*}\end{array}$ & $\begin{array}{l}\text { The pass rate assesses it. A } \\
\text { large } c_{i l} \text { shows the scheme has } \\
\text { a high pass rate in the } \\
\text { inspection. }\end{array}$ & $\begin{array}{l}\eta_{k} \text { is the pass rate of a } \\
\text { single tolerance type. }\end{array}$ \\
\hline Precision & $\begin{array}{c}c_{i 2}=u_{2}\left(s_{i}\right)=\sqrt{\frac{\lambda_{T}}{i d}} \\
(i=1,2, \ldots, n)^{*}\end{array}$ & $\begin{array}{l}\text { It is an estimation of the } \\
\text { design/assembly precision of a } \\
\text { feature. A small } c_{i 2} \text { indicates the } \\
\text { scheme has high precision. }\end{array}$ & $\begin{array}{l}\lambda_{T} \text { is the tolerance value } \\
\text { of the corresponding } \\
d^{* *} \text { (Table 11) and } I T \\
\text { (design tolerance grade) } \\
{[38]}\end{array}$ \\
\hline Applicative & $\begin{array}{c}c_{i 3}=u_{3}\left(s_{i}\right) \\
=\sqrt{\left|\lambda_{1} \ln \left(\lambda_{I T}\right)+\lambda_{2}-i\right|} \\
(i=1,2, \ldots, n)^{*}\end{array}$ & $\begin{array}{l}\text { It is modelled to balance the } \\
\text { precision and design function of } \\
\text { a feature. A small } c_{i 3} \text { indicates } \\
\text { that the scheme is appropriate. }\end{array}$ & $\begin{array}{l}\lambda_{I T} \text { is the value of the } \\
\text { corresponding tolerance } \\
\text { grades [38]; }\end{array}$ \\
\hline Verification & $\begin{array}{c}c_{i 4}=u_{4}\left(s_{i}\right)=\delta_{1} e^{\delta_{2} i} \\
(i=1,2, \ldots, n)^{*}\end{array}$ & $\begin{array}{l}\text { It is an estimation of } \\
\text { verification complexity. A large } \\
c_{i 4} \text { shows that the verification of } \\
\text { the scheme is complicated. }\end{array}$ & $\begin{array}{l}\text { the constant coefficients } \\
\lambda_{1} \text { and } \lambda_{2} \text { are determined } \\
\text { by inspection conditions }\end{array}$ \\
\hline Cost & $\begin{array}{l}c_{i 5}=u_{5}\left(s_{i}\right) \\
=\alpha_{1} e^{-\alpha_{1} c_{i 2}}+\alpha_{2} e^{-\frac{\alpha_{3}}{c_{i 2}}} \\
\quad(i=1,2, \ldots, n)^{*}\end{array}$ & $\begin{array}{l}\text { It is an estimation of the cost of } \\
\text { the device and manual. A small } \\
c_{i 5} \text { indicates that the scheme } \\
\text { costs low. }[41,42]\end{array}$ & $\begin{array}{l}\alpha_{0}, \alpha_{1}, \alpha_{2} \text { and } \alpha_{3} \text { are } \\
\text { determined by wages of } \\
\text { a worker, craft and } \\
\text { inspection method. }\end{array}$ \\
\hline
\end{tabular}

*: " $(i=1,2, \ldots, n)$ " means the order of the scheme in an $\boldsymbol{S}$. For example, to $\boldsymbol{S}_{\boldsymbol{z}}=\left[s_{z 1}, s_{z 2}, s_{z 3}\right], i$ of $s_{z 1}, s_{z 2}$ and $s_{z 3}$ is 1,2 and 3 respectively.

**: The definition of $d$ is illustrated in Table 11 for the estimation of the precision, which is referred to the literature [22].

Table 11 Determination of the length parameter of a feature

Features
$\begin{gathered}\text { Calculation methods } \\ \text { Plane }\end{gathered}$
The square root of the area of an integral
radial length of an integral feature.
Thevolving feature
Sphere
The largest length between two units pattern.
Pattern




\section{Appendix 3: The parameters in the case study}

Table 12 The parameters for estimation of attributes [46]

\begin{tabular}{cccc}
\hline Parameters & Plane & Revolving/Sphere & Pattern \\
\hline$\eta_{k}$ & 0.9973 & 0.9973 & 0.9973 \\
$I T$ & 6 & 6 & 6 \\
$\lambda_{1}$ & -1.762 & -1.762 & -1.762 \\
$\lambda_{2}$ & 5.518 & 5.518 & 5.518 \\
$\delta_{1}$ & 0.806 & 0.806 & 0.806 \\
$\delta_{2}$ & 0.196 & 0.196 & 0.196 \\
$\alpha_{0}$ & 5.075 & 17.315 & 8.237 \\
$\alpha_{1}$ & 25.207 & 47.540 & 35.805 \\
$\alpha_{2}$ & 1.686 & 1.792 & 1.307 \\
$\alpha_{3}$ & 0.0086 & 0.033 & 0.0083 \\
\hline
\end{tabular}

Table 13 The information value of each DP $[30,46]$

\begin{tabular}{cc}
\hline DPs & information value \\
\hline$D P_{1}(-)$ & 0 \\
\hline$D P_{2}(\square)$ & 0 \\
\hline$D P_{3}(\bigcirc)$ & 0 \\
\hline$D P_{4}(\varnothing)$ & 2.322 \\
\hline$D P_{5}(/ /)$ & 2.322 \\
\hline$D P_{6}(\perp)$ & 2.322 \\
\hline$D P_{7}(\measuredangle)$ & 4.322 \\
\hline$D P_{8}(\bigcirc)$ & $+\infty$ \\
\hline$D P_{9}(=)$ & 4.322 \\
\hline$D P_{10}(\phi)$ & 0.585 \\
\hline$D P_{11}(/)$ & 1.170 \\
\hline$D P_{12}(\llcorner)$ & $+\infty$ \\
\hline$D P_{13}(\bigcirc)$ & 4.322 \\
\hline$D P_{14}(\cap)$ & 4.322 \\
\hline$D P_{15}(\bigcirc)$ &
\end{tabular}

Note: Values of the parameters are listed as follow. $c_{v c}=5, c_{m}=7, c_{r m}=20, c_{c m m}=100, m_{v c}=$ $0.01, m_{m}=0.002, m_{r m}=0.002, m_{r m t}=0.003, m_{c m m}=0.001, V=0.004$, and $I_{p}=0$. 